\section{OUTCOME VARIATION AMONG Canadian trauma centres: TOWARD A CLINICAL PREDICTION RULE FOR STANDARDIZING APPROACHES TO CLINICAL ASSESSMENT OF HEMORRHAGE}

Dufresne and colleagues ${ }^{1}$ recently reported on the impact of trauma centre designation on patient-centred outcomes following hemorrhagic shock. The authors showed that patients treated at level I trauma centres had significantly lower odds of dying than those treated at lower-level centres - findings consistent with previous work. The authors hypothesized that differences in outcomes were associated with the initial assessment and management, where higher surgical volumes, greater clinical expertise and availability of resources, such as computed tomography (CT), could play an important role.

We agree that early recognition of hemorrhage is essential to allow aggressive, effective therapeutic interventions that can improve outcomes and reduce mortality. Although adoption of the Advanced Trauma Life Support (ATLS) guidelines could, in theory, contribute to the standardization of the initial evaluation for traumatic hemorrhage, the ATLS classification of hemorrhage has recently been shown to have poor overall accuracy, ${ }^{2}$ leading to overestimation of the presence of hypotension and tachycardia in bleeding patients. ${ }^{3}$ An international survey of ATLS course instructors found that only 1 in 10 respondents believed the ATLS classification to be a "good guide for fluid resuscitation and blood product transfusion."

We recently conducted a national survey of Canadian traumatologists as part of a larger project that aims to describe, understand and offer evidence-based refinement to this critical process through the development of a high-quality clinical prediction rule. The survey was electronically dis- tributed to all 153 Trauma Association of Canada staff physician members in April 2017. Respondents were asked to rank the top 5 variables predicting the need for major intervention (surgery, embolization, massive transfusion) in bleeding patients among clinical, laboratory or imaging available within the first hour of assessment.

We received responses from 52 of 153 clinicians (34.0\%). Most respondents were Canadian (86.5\%) and practised at level I (71.2\%), level II (17.3\%) or level III (11.5\%) equivalent trauma centres. The most common residency training programs completed were surgery $(67.3 \%)$ and emergency medicine (19.2\%). Hemodynamics was ranked within the top 5 predictors for all 52 respondents. Clinical examination, focused assessment with sonography for trauma (FAST), mechanism, blood gases and $\mathrm{CT}$ findings received top 5 ranks among more than half of respondents. In contrast, complete blood count, demographics and Glasgow Coma Scale score placed within the top 5 predictors for fewer than $10 \%$ of respondents.

The results from our survey show that the most highly ranked components of the hemorrhage assessment remain the classical "circulation" aspect of the primary survey in terms of patient hemodynamics and obvious sources of bleeding. Current practice preferences appear to align well with recently validated massive transfusion prediction scores. All 4 predictors (penetrating mechanism, systolic blood pressure $[\mathrm{BP}]$, heart rate and FAST) making up the Assessment of Blood Consumption $(\mathrm{ABC})$ score were ranked within the top 5 in our survey. Similarly, 5 of the 8 predictors (unstable pelvis, FAST, heart rate, systolic BP, base excess) making up the TraumaAssociated Severe Hemorrhage (TASH) score are also ranked quite highly. Interestingly, this observation is coupled with what appears to be the modernization of the trauma assessment — an evolving appreciation for CT imaging, which ranked just outside the top 5 .

Whereas some patients arrive in hospital in obvious extremis with a clear indication for urgent intervention, there remains a subset of the trauma population for whom the classical clinical and biochemical signs of hemorrhage may not be as readily apparent. As Dufresne and colleagues have alluded to, outcome differences among centres identified in their cohort are likely influenced by nonuniform approaches to traumatic hemorrhage assessment, whether related to limitations in resources or variable clinical expertise. This highlights the importance of establishing a practical, evidence-based and universally applicable tool for triage, assessment and determination of appropriateness for intervention in bleeding patients. The results from our survey will be used, together with a systematic review, ${ }^{5}$ to inform the specification and derivation of such a tool.

Alexandre Tran, MD; Maher Matar, MD, MHA; Jacinthe Lampron, MD, MPH; Ewout Steyerberg, PhD; Christian Vaillancourt, MD, MSc; Monica Taljaard, PhD.

Affiliation: From the Ottawa Hospital, Ottawa, Ont.

Competing interests: None declared.

DOI: $10.1503 /$ cjs. 1760051

\section{References}

1. Dufresne P, Moore L, Tardif P-A, et al. Impact of trauma centre designation level on outcomes following hemorrhagic shock: a multicentre cohort study. Can 7 Surg 2017;60:45-52.

2. Mutschler M, Nienaber U, Brockamp T, et al. the TraumaRegister DGU. Resuscitation 2013;84:309-13.

3. Guly HR, Bouamra O, Spiers M, et al. the Trauma Audit and Research Network. Resuscitation 2011;82:556-9.

4. Mutschler M, Hoffmann M, Wolfl C, et al. Is the ATLS classification of hemorrhagic shock appreciated in daily trauma care? An online-survey among 383 ATLS 
course directors and instructors. Emerg Med 7 2015;32:134-7.

5. Tran A, Matar M, Steyerberg EW, et al. Early Identification of patients requiring massive transfusion, embolization or hemostatic surgery for traumatic hemorrhage: a systematic review protocol. Syst Rev 2017;6:80.

\section{MAJOR LOWER-EXTREMITY AMPUTATIONS IN DIABETES: A RESPONSE TO "A CANADIAN POPULATION-BASED DESCRIPTION OF THE INDICATIONS FOR LOWER- EXTREMITY AMPUTATIONS AND OUTCOMES"}

After reading the report by Kayssi and colleagues ${ }^{1}$ that describes the nontraumatic lower-limb amputations in Canada during the 20062009 period, I would like to stress the importance of population-based studies focused in disease outcomes.

Despite the lack of clinically detailed information being the main limitation in the use of administrative databases, the research in this field is quite necessary because it brings a large panorama of quality of health care delivery, allowing regional and international comparisons as well.

Two findings of the aforementioned study are worth noting: diabetes was the leading cause of nontraumatic amputation in Canada (about $80 \%$ of the cases), and 1 of 3 cases corresponded to above-knee amputation (i.e., major lower-extremity amputations).

Major lower-extremity amputation is considered a devastating outcome in diabetes that reflects longstanding inadequate glycemic control and constitutes a strong indicator of the need to carry out medical interventions.

The characterization and even the control of amputations in patients with diabetes has been reached in some high-income countries, but the lack of epidemiological studies in most middleand low-income nations makes the management of the disease difficult.

In Mexico, major lower-extremity amputation in patients with diabetes is considered a growing public health problem that poses important challenges in terms of prevention, epidemiological characterization, medical treatment, and physical, social and emotional rehabilitation.

Iván de Jesús Ascencio-Montiel, MD, MSc

Affiliation: From Instituto Mexicano del Seguro Social, Coordinación de Vigilancia Epidemiológica, Mexico City, Mexico.

Competing interests: None declared.

DOI: $10.1503 /$ cjs.1760052

\section{References}

1. Kayssi A, de Mestral C, Forbes TL, et al. A Canadian population-based description of the indications for lower-extremity amputations and outcomes. Can 7 Surg 2016;59:99-106.

\section{AUtHOR REPONSE}

We thank Dr. Ascencio-Montiel for his interest in our study and agree with his comments regarding both the strengths and weakness of administrative databases. We agree that major amputation in diabetic patients is a global public health crisis, and we, and others, are actively pursuing multidisciplinary limb-preservation strategies. We applaud Dr. Ascencio-Montiel's efforts to do the same in Mexico.

\section{Ahmed Kayssi, MD, MSc, MPH \\ Affiliation: From the Department of Surgery,} University of Toronto, Toronto Ont.

Competing interests: None declared.

DOI: $10.1503 /$ cjs.1760053

\section{MY LATIN TEACHER: RESPONSE TO THE EDITORIAL “DATUM ISN'T, DATA ARE"}

As I read the editorial "Datum isn't; data are," I thought about why I already knew this: 4 years of Latin in high school. Although Latin was considered more a logic subject like mathematics than a foreign language course, as a teenager I was fully in agreement with the popular adage:

Latin is a language as dead as dead can be. It killed the ancient Romans and now it's killing me.

I had a teacher, Ms. Caughey, who taught carpe diem and collige, virgo, rosa (gather, girl, the roses) with a little extra emotion and put it on an exam, as I thought she would. I got a good mark on that test. It was only in medical school that I began to appreciate the value of her teaching, as I struggled to learn medicine and memorize the overload of data in seemingly endless didactic lectures. The medical vocabulary based on Latin was the only easy thing. Albino (L. albus), supinate (L. supino), pronate (L. prono), ulcer (L. ulcus) were just common sense and did not require study.

I did not thank her personally, and she is one of many teachers I should have thanked. She was a classic subject for this quote of Henry Adams':

A teacher affects eternity. $\mathrm{He} / \mathrm{she}$ can never tell where his/her influence stops.

\section{Dennis F. Pitt, MD}

Affiliation: Department of Surgery, the Ottawa Hospital, Ottawa, Ont.

Competing Interests: None declared.

DOI: $10.1503 /$ cjs. 1760054

\section{References}

1. McAlister VC. Datum isn't; data are. Can $\mathcal{F}$ Surg 2016;59:220-1.

\section{A USEFUL SET OF GUIDELINES: A RESPONSE TO "TOWARD LATE CAREER TRANSITIONNING: A PROPOSAL FOR ACADEMIC SURGEONS"}

In this issue of C7S, Richards and colleagues ${ }^{1}$ propose a series of guidelines regarding late career transitioning for academic surgeons as they approach the end of their academic surgical 